\title{
Indian Color Symbolism: A Demonstration of Color Metaphors With Visual Identity
}

\author{
Neha Singh, Ashima Tiwari \\ National Institute of Fashion Technology, New Delhi, India
}

\begin{abstract}
Colors play a very important role in our lives as they evolve emotions. The colours can make us feel happy or sad, as well as make us feel hungry and relaxed. They have the ability to affect our emotions and mood in a way that few other things can. They posses symbolic association in context of specific cultures. İn other words, a particular culture beholds a specific vocabulary of color's association based on the ethnography. In this research paper, authors have tried to understand the meanings of color on the basis of ethnographic differences, age, and work cultures.
\end{abstract}

Keywords: color association, visual identity, ethnography

\section{Introduction}

Colors manifest cultural values and have always been associated with emotional context. We can see over seven million colors. These are formed by mixing three building blocks; red, yellow, and blue in different proportions, are termed as primary colours. A single color can have diverse meanings in varied cultures. A vast range of colour association and symbologies are present in India due to its multifold cultural background. Context is everything: a group or community of people wearing black might be part of family function or may be mourners. The traditional meanings associated with colors in various cultures of India have a significant associations and their reflection on the society.

The global impression of India beholds its colorful culture, streets, and stories and it always seems like a page out of an ancient folk tale. India represents simple expressions of colors, holding together multitude of outlooks, lifestyles, and traditions. A peculier colour symbology is an integral part of all cultures and it holds an significant space in different aspects of life, it is in religion, politics, festivals, or celebrations. In India, whatever is in the north, south, west, or east, color and culture go hand in hand. Just like many other cultures across the world, a distinctive taxonomy of color associations is treasured in India.

Samples of 100 professionals (male and female) with diverse cultural background in the age group of 25 to 35 were randomly selected. Questionnaire and personal interview tools were used to collect the information. By using decriptive research method, a number of conclusions were drawn by analysing the collected data.

\section{Colour and Religion}

With so many diverse religions, few colours still travel parallel in all. Considering the bridal wear, red is

\footnotetext{
Neha Singh, Ph.D. in Clothing and Textiles, Assistant professor, Department of Textile Design, National Institute of Fashion Technology.

Ashima Tiwari, Maters in Design, Assistant professor, Department of Textile Design, National Institute of Fashion Technology.
} 
always preferred as an auspicious colour in Hindu, as well as in Muslim communities. In Hindu religion, red is of utmost significance and the colour most frequently used for auspicious occasions like marriages and festivals, etc. A red mark is put on the forehead during ceremonies and important occasions. The universal application of red dot Bindu on the forehead is the outward token of psychic energies. White is considered as colour of mourning, contrary to this, white is adorned by male members of the family while performing various rituals pertains to child birth and sacred thread ceremonias. In Christianity, black is considered as the colour of mourning, red represents blood and war and white is considered as auspicious, pure and the colour of righteousness.

In present context, India is observing a subtle shift in colour preference patterns due to the presence of contrast between preconceived notions inherited from ancestors and influence of other cultures with contradictory wisdom. For instance, white was considered as mourning colour or "no colour" in Hindu culture, however, it is nowadays preferred as a prevalent colour in combination with other vibrant hues in ritualistic ceremonies. In contemporary view, white is accepted to be used for bridal wear in north Indian Hindu culture which was forbidden in earlier time.

\section{Kaleidoscopic Allure}

Being heterogeneous in nature, varied colours are used together creating a layered effect which expresses the Indian philosophy of living together and exchange of colours between cultures. In keeping with the philosophy of synthesis, violent contrasts are everywhere harmonized in all aspects of lifestyle. One colour seen through the other creates an almost kaleidoscopic effect. The Indian designers with inherited design and colour sensibilities always try to bring back the peculiar traditional colours and techniques, presented in contemporary form based on western trends, are always cherished by population. In digital era, with the presence of social media and online shopping, people have access of global trends on their tabs and phones. What a Hollywood or Bollywood celebrity wore today afternoon will be out on media in the next hour. This makes people to rethink on their colour choices, in spite of having traditional preferences. Presently the cross cultural population is well aware of global fashion through social media, hence they observe and adapt global colour trends easefully. The presence of Indian celebrities on red carpet in Cannas Film Festival showcased a new colour palette to be followed by masses. Aishwarya Rai Bachchan, Miss World 1994 and an Indian Bollywood actress, who completed her 15 years at Cannes this year, shocked everyone by putting up a Purple lipstick. While the majority found it amusing, there were others who praised her experimental look and the colour was followed by the people appretiative of trendy chic. The Economic Times also stated that "Neons are a thing of past as pastels takes over" (Rathore \& Bailay, 2014). India may be the most colourful country with vibrant colours dominating our Indian dresses, festivals, and even streets, yet the country's fashionistas are giving up their bright, in-your-face neons for soft, milky pastel hues this summer season.

\section{Colour and Gender}

With presence of chalk and cheese societies, metro cities play an important role in setting the trends and preferences of colours in India. Majorly, gender differences in color sensitivity are not prominently related to cross-cultural localization. A closer look, however, will reveal that these are found in every society, each with some specific characteristics. The brands staging of blue and pink associated with male and female, had a great impact on choices of colours. Unconsciously the parents are also responsible in cultivating the notion of gender 
biased colour preference in their wards. From the childhood the notion of boys preferring blues and girls appreciating pinks is prevalent in society.

Indian contemporary fashion stylists are paying an important role in changing these norms. For example, a Bollywood actor, Ranveer Singh, has changed the entire classification of colours and prints for men. By wearing a pink, Chinese collar men suit with a brown flared skirt during the promotion of his highly awarded film "Bajirao Mastani", he has introduced a new dictionary of colours for Indian men and broke the boundaries of stereotypes.

\section{Colour and Work}

In the new era of cooperate world with more working professionals, people accepted neutrals and saturated tones, such as black, grey, and white in their wardrobes apart from bright hues. Indian women in metro cities are adapting neutral look as per the demand of the working environment. The definition of "being dressy" is also changing in the psyche of contemporary masses. For instance, the Indian woman's wear sari traditionally worn in bright hues, at present adorned in neutral colours also during formal occasions. Contrary to this, in earlier time, the neutrals coloured saries were worn by widows and elderly females of the family.

\section{Conclusions}

A decriptive research was carried out to explore the various facet of cross cultural impact on colour preference. However a generic notion about certain colors associated with specific characteristics appears in different versions speaking universal language of togetherness. The results reveal that colour preference pattern is changing in present scenario retaining essence of traditional beliefs and meanings. The society is observing exchange of colour beliefs and mutually valuing the colour associations between cultures with a modern twist.

\section{Reference}

Rathore, V., \& Bailay, R. (2014). The Economic Times Bureau, May 31. Bennett, Coleman \& Co. Ltd. 